\title{
AL-A'RAF
}

Jurnal Pemikiran Islam dan Filsafat

SURAKARTA

http://ejournal.iainsurakarta.ac.id/index.php/al-araf

ISSN: 1693-9867 (p); 2527-5119 (e)

DOI: 10.22515/ajpif.v14i2.481

\section{EKSISTENSI MAJAS DALAM ALQUR'AN SEBAGAI KHAZANAH KEILMUAN ISLAM}

\section{Moh. Muhtador Nawafi \\ STAIN Kudus}

\begin{tabular}{l}
\hline \\
\hline Keywords: \\
Majaz, Discourse, \\
and Islamic Studies
\end{tabular}

\begin{abstract}
Abstrak
Amin Alkhulli memetakan kajian Alquran menjadi dua tema besar, dirasat ma hawl Alquran dan dirasat fi Alquran nafsih. Dari klasifikasi ini terlihat bahwa majas menjadi bagian dari kajian yang kedua. Majas dikategorikan Alkhulli sebagai bagian dari sturuktur tata bahasa teks Alquran. Dengan menjadikan teks Alquran sebagai sebuah obyek kajian, maka keberadaan majas akan memberikan beragam wacana. Teori bahasa memberikan dua pandangan terkait majas, pertama menyatakan bahwa Alquran tidak mengandung majas, karena majas diindikasikan memuat kebohongan. Padahal tidak mungkin Alquran memberikan berita bohong. Kedua, bahwa majas terdapat dalam teks-teks Alquran, karena mengindikasikan keanggunan dan ketinggian ekspresi bahasanya. Di sinilah fokus kajian dari artikel ini, dimana majas selain menjadi bagian dari teks Alqur'an, juga menjadi bagian dari diskursus kajian studi Islam.
\end{abstract}

\begin{abstract}
Amin Alkhulli was mapping out the qur'anic studies into two big themes, dirasat ma hawl Alquran dan dirasat fi Alquran nafsih. From this classification could be seen that majaz as part of the second studies. Majaz was categorized by Alkhulli as part of the Qur'anic text grammatical structure. Making the qur'anic text as an object of the study, therefore the existence of majaz will give various discourses. The linguistic theory gave two perspectives on this, first stated that Alqur'an was not contended majaz, because majaz indicated to have the untruth content, whereas it was impossible for Alquran to give the improper information. Second, majaz was existed inside the qur'anic texts, because it was indicating the elegant and high expression of language. Here is the focus of this article, wherein besides of becoming part of the qur'anic text, majaz was also becoming Islamic studies discourses.
\end{abstract}




\section{Pendahuluan}

Membahas majas akan mengembalikan keilmuan pada dasar aspek kebahasaan, karena majas adalah bagian dari ilmu bahasa. Tulisan ini akan membahas tentang majas dalam tata bahasa Alqur'an. Alqur'an adalah firman Allah yang diturunkan kepada Nabi Muhammad saw., dan diyakini oleh umat Islam sebagai rujukan utama dalam menjalani kehidupan. Bahasa Arab digunakan sebagai bahasa Alqur'an dengan tujuan agar memberikan kemudahan bagi masyarakat setempat untuk memahami pesan yang terkandung di dalamnya. Oleh sebab itu, Alqur'an menjadi bagian dari kehidupan masyarakat Arab. ${ }^{1}$ Alqur'an diturunkan di Arab bukanlah semata-mata kebetulan. Alqur'an hadir dalam konteks merespon kondisi sosial yang sangat kompleks saat itu. Di saat peradaban Arab awal telah berkembang pesat, terutama dengan perkembangan sastranya. ${ }^{2}$

Kajian majas dalam hal ini bukan dalam rangka mendekonstruksi teks Alqur'an, tetapi sebagai usaha dalam memahami pergulatan pemikiran dalam dunia Islam tentang kajian Alqur'an. Sebab Alqur'an secara logis merupakan bagian dari budaya Arab. Oleh sebab itu, secara gramatikal, Alqur'an pun mengikuti gramatikal Arab. Tetapi apakah Alqur'an harus mengikuti kaidah bahasa Arab atau tidak, terutama dalam hal majas, merupakan sebuah pertanyaan menarik. Perdebatan dalam hal ini menyentuh bagian dari keilmuan Islam, seperti para Ushuluyyin dan Lughawiyin. Perdebatan panjang yang disajikan, menentukan eksistensi bahasa sebagai media yang harus tetap dijaga dan dicurigai, tentunya dengan konteks dan kompleksitas munculnya bahasa itu sendiri.

1 Nasr Hamid Abu Zaid, Naqd Alkhitab Aldiniy (Kairo: Maktabah Matbuli, 1992), 5-8.

2 Syah Waliyullah Aldahlawi, Alfauzul Alkabir fi Ushul Altafsir (Kairo: Darh Syuhuh, 1986), 31. 


\section{Definisi Majas}

Sebagai usaha untuk menjadikan agar kajian ini tidak parsial, dan mempunyai pijakan dalam mengambil kesimpulan, maka pembahasan dalam artikel ini diawali dari definisi tentang majas. Menurut ulama balaghah, kata majaz, secara bahasa terbentuk dari kata jaza, yang mengandung makna "melewati tempat tertentu". Tetapi secara istilah, bisa dilihat dari pernyataan berikut:

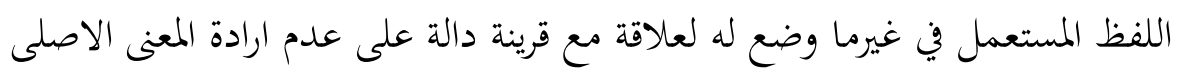

Jika diterjemahkan secara bebas, akan berarti "lafal (kata) yang digunakan, bukan pada tempatnya, karena adanya hubungan dengan petunjuk yang menunjukkan, bukan pada makna aslinya". ${ }^{3}$ Definisi ini masih sangat umum, karena tidak ada batasan-batasan tertentu yang menjelaskannya secara detil. Tetapi para ahli ushul berpendapat, bahwa majas adalah penggunaan kata yang sulit dipahami oleh para pendengarnya. Sebagian lagi mengatakan, bahwa majas adalah mensifati sesuatu dengan sesuatu yang bukan aslinya. ${ }^{4}$

Kedua pandangan tersebut berangkat dari berbagai disiplin keilmuan para ulama ketika memberikan definisi tentang majas. Secara umum, keduanya mempunyai kesamaan makna, dimana majas diartikan sebagai suatu ungkapan dengan menggunakan kata, yang biasanya tidak lumrah bagi kebanyakan orang. Sehinga perlu penjelasan dari petunjuk atau hal lain. Namun ketika mengkaji Alqur'an dari aspek majas, kedua definisi tersebut terasa ambigu. Sebab definisi harus mempunyai batasan yang jelas ketika memahami Alqur'an, sebagaimana terlihat di bawah ini:

"Majas adalah suatu lafal (kata atau kalimat) yang mengandung makna bukan sebagaimana arti yang berlaku dalam bidang pembicaraan tertentu, karena adanya hubungan antara makna yang pertama dengan makna yang kedua. ${ }^{5}$

3 Ahmad Hasyim, Jawabir Albalaghah fi Alma'ani Wa Albayan Wa Albadi' (Libanon: Darul Kutub Alilmiyah, 1971), 177.

4 Abi Ishaq ibn Ali ibn Yusuf, Alluma' fi Ushul Figh (Semarang: Taha Putra, n.d.), 5.

5 Sukamta, Majaz, dan Pluralitas Makna dalam Alquran (Yogyakarta: Adab Press UIN Sunan Kalijaga, 2009), 50. 
Ragam tawaran definisi yang dikonstruk oleh berbagai disiplin keilmuan dalam Islam, menunjukkan bahwa pembahasan tentang majas, selain memerlukan kehati-hatian juga sangat menarik. Dari berbagai definisi di atas, bisa dilihat kesemuanya merujuk pada satu arah, yakni penggunaan majas dalam bahasa merupakan suatu keniscayaan yang sering dilekatkan pada sifat sesuatu pada sesuatu yang lainnya. Seperti contoh "Umar macan padang pasir" penggunaan kata "macan" yang dilekatkan pada Umar, bukan berarti Umar adalah benar-benar seekor macan. Namun sifat keberanian dan kegagahan yang dimiliki Umarlah yang disamakan dengan macan, sebagai hewan yang gagah dan pemberani.

Namun tidak semua kata atau kalimat yang dilekatkan pada sesuatu dapat dinamakan majas. Misalnya kalimat "Ali putih". Kalimat ini tidak dapat dinamakan majas, sebab masih ambigu untuk menginterpretasikannya. Sebuah kata/kalimat dapat dikatakan sebagai majas harus memenuhi unsur-unsur antara lain, keterkaitan, kesamaan, batasan, dan kesepakatan. ${ }^{6}$

Dalam perkembangannya, sejarah bahasa harus dicurigai sebagai usaha dalam mengkonstruksi keilmuan Islam. pasalnya, perkembangan keilmuan dari satu masa ke masa berikutnya selalu mempunyai keterkaitan. Begitu pula mengenai eksistensi majas dalam Alqur'an. Oleh sebab itu dibutuhkan pembahasan embrio dalam kesejarahan majas secara umum. Hal ini dimungkinkan agar pengungkapan makna estetika, atau sering disebut majas tidak hanya lahir dari dunia Islam. ${ }^{7}$

\section{Perkembangan Majas}

Perdebatan seputar majas berawal dari asumsi awal yang menyatakan, bahwa tidak ada majas dalam bahasa secara keseluruhan. Menurut Abu Ishaq Alisfaraini dan Abu Ali Alfarisi, Majas dianggap mengandung sebuah

\footnotetext{
6 Ahmad Hasyim, Jawahir Albalaghah fi Alma'ani wa Albayan Wa Albadi', 177.

7 Sahiron Syamsuddin, Hermeneutika dan Pengembagnan Ulum Alquran (Yogyakarta: Wanesia, 2009), 11.
} 
kekosongan dan kebohongan, yang pada akhirnya akan menimbulkan fitnah. $^{8}$

Pendapat berseberangan dikemukakan Abu Ubaidah, bahwa majas adalah bagian dari keindahan dalam berbahasa. Kedua pendapat tersebut memiliki konsekuensi logis ketika hendak memahamai ayat-ayat Alqur'an yang menimbulkan perdebatan teologis. Ayat-ayat tentang sifat Allah menjadi perdebatan sepanjang sejarah keilmuan Islam, sebagaimana saat para mufasir, baik dari golongan ushuliyin atau lughawiyin hendak menafsirkan ayat seperti Q.S. Alfath 10, selain perdebatan terkait status ayat tersebut mubkamat atau mutasyabihat. ${ }^{9}$ Namun Ibnu Jarir menafsirkan ayat tersebut dengan dua makna: pertama, mengindikasikan kekuasaan Nabi sebagai orang yang mempunyai otoritas agama, dan kedua menjelaskan kekuasaan Allah berada dibalik peran Nabi. ${ }^{10}$ Pemahaman tersebut diperkuat oleh Zamaksyari yang berpendapat, bahwa Allah adalah Dzat yang tidak mempunyai sifat cela, sehingga meyakini Nabi sebagai utusan, sama halnya dengan meyakini kekuasaan Allah. ${ }^{11}$

Terlepas dari perdebatan dan penafsiran di atas. Sejarah mencatat, bahwa majas telah digunakan jauh sebelum Islam dan Alqur'an diturunkan. Namun penggunaan majas pada masa awal terbatas pada kajian kitab suci, mitos, dan hukum. Bersamaan dengan hal tersebut, majas dalam bidang bahasa juga sudah dikenalkan oleh Philo Van Alexandrien pada tahun pertama Masehi. ${ }^{12}$

Kajian majas dalam Alqur'an merupakan disiplin ilmu tersendiri yang terus berkembang, seperti halnya ilmu-ilmu bahasa pada umumnya.

8 Muhammad Amin ibn Muhammad Mukhtar ibn Abdul Qadir Aljakni Alsangqithi, Man'u Jawaz. Almajaz fi Manzi Alta'abud wa I'jaz. (Kairo: Darul Ilmi Alfuadi, n.d.), 5 .

9 Muhammad Amin ibn Muhammad Mukhtar ibn Abdul Qadir Aljakni Alsangqithi, Man'u Jawaz. Almajaz fi Manzi Alta'abud wa I'jaz, 63.

10 Muhammad ibn Jarir ibn Yazid Abu Ja'far Althabari, Jami' Albayan fi Ta'wil Alquran (Beirut: Muasasah Alrisalah, 2000), 173.

11 Alqasim Mahmud ibn Umar ibn Ahmad Alzamakhzyari, Alkasysyan Haqaiq Ghawam Altanzil (Beirut: Dar Kutub, n.d.), 743.

12 Sahiron Syamsuddin, Hermeneutika dan Pengembagnan Ulum Alquran, 12. 
Perkembangan tersebut bersamaan dengan penyebutan majas dalam ilmu keislaman, khususnya ulum Alqur'an. Kata majas dalam kajian Alqur'an adalah hal baru. Kata tersebut baru ditemukan dan diperkenalkan oleh Abu Ubaidah Mu'ammar Almusanna (meninggal pada tahun 210 Hijriyah). Dalam perkembangannya, majas dalam Alqur'an dapat dibagi ke dalam tiga (3) fase. Pertama, fase pengenalan makna, yaitu masa dimana kata amtsal lebih banyak dikenal oleh masyarakat Islam awal dibanding dengan majas. Fase ini banyak ditemukan pada masa sahabat, bahkan pernah ada pada masa Nabi. Pada masa ini, bukan berarti sahabat dan Nabi tidak mengenal majas, tetapi penggunaan kata memiliki kemiripan makna atau maksud yang sama dengan majas. Hanya saja lebih familiar dengan sebutan amtsal. Di antara yang menggunakan istilah amtsal (sekarang lebih dikenal dengan istilah majas) ialah Ibnu Abbas, Mujahid, dan Qatadah. ${ }^{13}$

Fase kedua, ialah fase penyusunan majas yang sifatnya lebih umum. Penyusun kitab pertama tentang majas terjadi pada abad kedua (2) Hijriyah, yaitu Muqatil bin Sulaiman (meninggal 150 Hijriyah) dengan karyanya yang berjudul Alsybah wa Alnadha'ir. Pada masa ini, Muqatil berusaha mengungkap keragaman makna dalam Alqur'an dari satu kata/kalimat (lafad₹). Di sini ia tidak membahas tentang hubungan kesamaan satu lafad₹. dengan yang lainnya, meski berusaha mengungkap kandungan makna yang melekat pada makna yang lain, dengan konteks diturunkannya ayat. ${ }^{14}$

Fase ketiga ialah fase pematangan majas yang dikenalkan oleh Abu Ubaidah Mu'ammar Almusanna (meninggal 210 Hijriyah), dengan karyanya yang berjudul Majaz. Alqur'an. Majas yang ada pada masa tersebut, tidak seperti majas yang dikenal pada masa sekarang. Majas yang berkembang pada saat ini ialah lawan dari haqiqah, sementara majas yang dimaksud ole Ibnu Qutaibah ialah cara orang-orang Arab mengungkapkan

13 Nasr Hamid Abu Zaid, Menalar Firman Tuban, Wacana Majaz dalam Alqur'an Menurut Mu'tazilah (Terj), ed. Abdurahman Kasdi dan Hamka (Bandung: Mizan, 2003), 138.

14 Zarkasyi, Alburban fi Ulum Alquran (Beirut: Dar Kutub, 1999), 73. 
maksud dan tujuan dalam bentuk bahasa. ${ }^{15}$ Sehingga majas tidak diartikan sebagai pemindahan makna lafadz, karena majas yang dimaksud masih umum, mencakup masalah istia'arah, qalb, taqdim, ta'khir, ha:f, dan kinayah. Penggunaan kata yang mempunyai arti khusus, tapi bermakna umum dan sebaliknya. ${ }^{16}$

Untuk masa selanjutnya, majas mengalami perkembangan cukup pesat, dari yang awalnya hanya kajian uslub bahasa, kini majas dalam Alqur'an menunjukkan atas penggunaan makna yang diumpamakan, atau dengan bahasa yang mudah dipahami, majaz menjadi lawan dari haqiqi.

Berbeda denga Abu Ubaidah, Alfarra' (meninggal 209 Hijriyah) datang dengan konsep Tajawmuzuntuk menunjuk lafadzyang menggunakan makna majas, meskipun konsep tersebut belum diberi batasan yang jelas. Namun pemikiran Farra' tentang Tajawwuz sama dengan konsep majas yang berkembang pada saat ini. Misalnya, saat ia mencontohkan kata sujud dalam Q.S. Alimron, sebagaimana berikut:

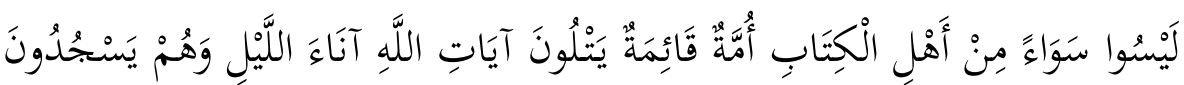

Dalam pandangan Alfarra', kata yasjudun di atas bukan bermakna sujud yang sebenarnya. Pasalnya, dalam sujud tidak membaca ayat Alqur'an. Jadi kata sujud di sini lebih berarti shalat, dan itu sama dengan konsep majaz, mursal.

\section{Majas sebagai Khazanah Keilmuan Islam}

Membincangkan majas dalamkeilmuan, seakan-akanmembincangkan sekte keilmuan Islam. Kekuatan analisa majas hanya terfokus pada dua kekuatan. Pertama, ahli bahasa, dan kedua kelompok ushul fiqh. Meskipun demikian, kedua kelompok tersebut mempunyai keunikan disertai dengan argumentasinya masing-masing.

15 Abiet Aljabiri, Binyat Alaql Alarabi, Dirasah Tabliyyah Naqdiyah li Nuzum Alma'rifahfi Altsaqafah Alarabiyah (Beirut: Almarkaz Astsaqafi, 1991), 21.

16 Abu Ubaidah, Majaz, Alquran (Kairo: Maktabah Nasher, n.d.), 16-19. 
Dalam perspektif usul fiqh, secara definitif telah dijelaskan sebagaimana di atas. Sementara secara ushul, majas lebih dilihat dari perspektif epistemologi. Dalam kitab ushul, majas termasuk dalam bab pembahasan tentang "pembagian kalam" dan bersanding dengan pembahasan haqiqab. ${ }^{17}$ Dari sekian contoh yang diberikan, para ulama' ushul sering menggunakan majas dalam Alqur'an, sebagaimana terdapat dalam Q.S. Alkahfi 77, berikut ini:

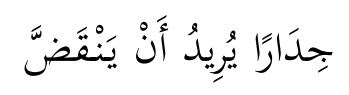

Dalam kajian ushul, ayat ini adalah bagian majas, dan untuk dapat memahaminya harus menggunakan kajian bahasa. Atas dasar itulah, para Ushuliyun membagi majas ke dalam empat (4) bagian; majaz isti'arah, majaz. nuqsan, majaz ziyadah, dan majaz naqli. Kompleksnya ilmu keislaman yang sudah ada sejak zaman Nabi, yang dapat berinteraksi dengan keilmuan lain tidak bisa menafikan majas. Majas dianggap sebagai salah satu ungkapan yang mengandung nilai tinggi dalam ilmu kesusastraan. Argumentasi tersebut menepis anggapan yang menyatakan, bahwa tidak ada majas dalam keilmuan bahasa secara umum dan maupun dalam Alqur'an. Mengingat Alqur'an turun dalam konteks pesatnya peradaban sastra.

Meski sebagian ahli bahasa menyetujui pendapat di atas, namun terdapat perbedaan metode dalam menilai penggunaan majas. Dalam kajian bahasa, majas adalah komponen penting dalam mengungkapkan sesuatu dengan penghormatan, atau untuk memalingkan prasangka. Meskipun sebagian menolak majas dalam bahasa, terutama dalam Alqur'an, namun melihat ragam ungkapan yang terdapat dalam Alqur'an, serta mempertimbangkan konteks dimana Alqur'an turun dan bagaimana diturunkan, sangat mungkin adanya majas dalam Alqur'an. Karena tidak mungkin Tuhan menggunakan bahasa yang sederhana dalam firman-Nya.

${ }^{17}$ Dalam bab ini dibahas bahwa ungkapan itu mengandung dua unsur, pertama ada perkataan yang tidak dapat dimengerti atau tidak mengandung faidah (mubmal), disisi lain ada pembicaraan yang dapat dimengerti dan mempunyai faidah yang selanjutnya disebut musta'mal. baca Abdul Malik bin Abdullah Al- Juwaini, Alwaraqat fi Ushul Alfiqh (Surabaya: Alhidayah, 1999), 4. 
Mengingat keadaan sosio-kultural dunia Arab saat itu yang sasatranya cukup pesat berkembang.

Di sisi lain, ungkapan-ungkapan Alqur'an yang penuh dengan nuansa sastra tidak dapat ditandingi oleh masyarakat Arab pada masa itu. Alqur'an memiliki nilai sastra tinggi yang tidak dimiliki oleh masyarakat Arab saat itu. Bahkan dalam konteks tertentu, Alqur'an juga memberikan tantangan kepada manusia (khususnya masyarakat Arab yang meragukan Alqur'an) untuk membuat satu ayat dengan nilai sastra yang sepadan dengan kandungan sastra dalam Alqur'an. Namun tidak satupun dari mereka yang bisa menandingi ungkapan-ungkapan yang ada di dalam Alqur'an. Oleh sebab itu, tidak bisa dipungkiri adanya majas dalam bahasa Alqur'an. Maka dari sinilah para ahli bahasa membagi majas ke dalam empat (4) bagian, majaz mufrad mursal, majaz mufrad istiarah, majaza murakkab mursal, dan majaz. murakkab istiarah.

\section{Wacana Majas dalam Alquran}

Secara umum, sejarah wacana majas dalam keilmuan Islam dapat dibagi menjadi tiga (3) bagian. Pertama, mempertahankan majas secara keseluruhan, dengan argumentasi bahwa majas sebagai bagian dari keindahan bahasa. Selain itu, ada pula argumentasi yang menyatakan bahwa bahasa adalah kreasi manusia, yang secara alamiah sepenuhnya dimiliki oleh umat manusia. Namun ini tidak berarti bahwa Alqur'an menggunakan bahasa manusia yang mengabaikan sifat transendental Tuhan, meskipun bahasa Alqur'an menggunakan bahasa sebagai bahasa masyarakat setempat. Dengan demikian, terjadi dialektika antara firman Allah dan budaya masyarakat setempat.

Kedua, kelompok yang menolak majas secara keseluruhan, baik dalam bahasa maupun dalam Alqur'an. Argumentasi kelompok ini adalah bahwa secara keseluruhan bahasa Arab dalam Alqur'an itu adalah bahasa Allah yang tidak bisa dianalisa oleh manusia dengan logikanya. Meskipun tidak dapat pungkiri bahwa Alqur'an menggunakan bahasa Arab. 
Ketiga, kelompok yang mengakui konsistensi atau keberadaan majas dalam kondisi tertentu, dan di bawah persyaratan tertentu. Prasyarat dan ketentuan ini didasarkan pada ragam bahasa Alqur'an. Satu sisi, Alqur'an sebagai firman Allah dengan hak prioritas-Nya dan tidak dapat dianalisa dengan logika manusia. Tetapi pada disisi lain, Alqur'an telah menjadi bahasa bumi, bahasa manusia, dan menggunakan bahasa Arab.

Dalam konteks ini, majas dalam Alqur'an yang dimaksud adalah dengan menempatkan Alqur'an sebagai bagian dari kitab sejarah, tetapi bukan buku sejarah, bukan pula kitab sastra, dan bukan pula buku sastra. Dengan kesadaran sejarah Alqur'an yang bergelut dan berinteraksi dengan masyarakat Arab pada masa itu, maka wajar kalau Alqur'an berbahasa Arab. Sebagaimana sudah ditegaskan dalam Q.S. Ibrahim ayat 4. Meski menjadi bagian dari bahasa dan tradisi Arab, tetapi transendensi Alqur'an sebagai kalam Ilahi tidak akan pernah hilang. Jika dilihat dari sisi bahasa, manusia juga mengungkapkan eksistensi majas sebagai bagian dari bahasanya, maka Alqur'an pun mengandung majas seperti halnya bahasa Arab, sebagaimana yang digunakan oleh masyarakat Arab pada masa itu. Seperti ungkapan salah satu pujangga Arab berikut ini: ${ }^{18}$

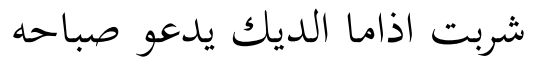

Konsekuensi ini berdampak pada tatanan Alqur'an yang juga menggunakan majas. Dalam Alqur'an sendiri, secara umum majas dapat dibagi menjadi tiga (3), pertama, majaz isnadi, termasuk di dalamnya majaz. hazfi. Yakni, majas yang berhubungan dengan penyandaran satu kata terhadap kata yang lain, bukan kata perkata secara individual. Adapun yang dimaksud dengan majaz isnadi ialah menyandarkan kata kerja, atau yang mempunyai arti kerja kepada penyebab perbuatan, tempatnya atau bentuk masdar-nya, atau menyandarkan isim mabni lil fail kepada maf'ul (obyeknya) atau sebaliknya menyandarkan isim mabni lil maf'ul kepada failnya. ${ }^{19}$

18 Abu Ubaidah, Majaz, Alquran, 45.

19 Ali Aljarim dan Mustafa Amin, Albalaghah Alwabidah (Kairo: Dar Alma'arif, 
Atas dasar kaidah atau pengertian tersebut, dapat dipastikan bahwa bentuk dan ragam majaz isnadi yang terdapat dalam Alqur'an sangat banyak. Sebagai contoh misalnya kalimat وَاسأًَْل الْقَيَيَة yang menunjukkan pada majas had:f, atau dalam bahasa ushul fiqh ialah majas naqis, seperti dalam Q.S. Yusuf ayat 12. Dimana dalam lafadz tersebut mudhaf-nya dibuang dan langsung menggunakan mudhaf ilaih sebagai ganti. Padahal yang dimaksud ialah mudhaf.

Kedua, ialah majaz lughawi, termasuk di dalamnya majaz isti'arah dan majaz, mursal, yang secara individu mencakup isim, fiil, dan barf. Disebutkan bahwa majaz lughawi yang hanya terkait dengan kata per kata secara individual merupakan penggunaan terhadap suatu lafadz untuk arti kedua, bukan arti pertama, tetapi di antara keduanya ada hubungan tertentu. Jika hubungan tersebut bersifat musyabahah, maka dapat dikatakan sebagai majas isti'arah. Tetapi apabila tidak ada hubungan, maka sifat musyabahah antara yang satu dan yang lainnya dapat dikatakan sebagai majaz, mursal. Oleh sebab itu, tidak jauh berbeda dengan majaz isnadi, majaz lughawi pun memiliki beragam bentuk.

Dasar dari keterkaitan majaz lughawi adalah pengaruh konteks dan qarinab lafadz yang terdapat dalam teks itu sendiri, dan pilihan pengarang untuk memudahkan pemahaman pembaca dalam memahami ide dasar Tuhan, yang disesuaikan dengan kemampuan manusia. Kalau kata yang terdapat dalam contoh langsung ditawarkan sebagai agama, maka pembaca akan menemukan makna abstraknya. Tetapi hal berbeda akan ditemukan, ketika jalan lurus yang ditawarkan, sebab jalan lurus menunjukkan atas sesuatu yang baik.

Ketiga, majaz khitabi, membahas gaya bahasa yang digunakan untuk menyampaikan makna yang kompleks dengan wacana tertentu, mencakup perumpamaan, kisah yang menggambarkan sketsa kehidupan, ataupun hal yang lebih luas. Karena teks menjadi bagian dari kehidupan dan rumusan

1951), 117. 
budaya tempat lahirnya, maka dapat dikatakan bahwa teks mempunyai beberapa unsur yang melingkupinya. ${ }^{20}$ Tidak jauh berbeda dengan Alqur'an yang telah menjadi bagian dari teks Arab, namun dengan tanpa menghilangkan transendentalitas Alqur'an sebagai kalam Tuhan. Salah satu contoh bisa dilihat dalam pembicaraan sederhana Alqur'an yang ingin mungungkapkan kandungannya kepada manusia, dengan pemahaman manusia. Maka dapat dikatakan bahwa bahasa Alqur'an menyesuaikan pola pikir manusia pada masa itu. Salah satunya dengan menggunakan ungkapan berbentuk majas.

Selain itu, terdapat kandungan makna di dalam Alqur'an yang disebut sebagai makna tersurat dan makna tersirat. Makna tersurat ialah makna literal yang terdapat dalam kumpulan ayat. Sementara makna tersirat lebih memilih kandungan ayat secara keseluruhan untuk mencari substansi pesan yang hendak disampaikan. Majaz khitabi dimasukkan di sini sebagai bagian dari kandungan makna substantif yang terkandung dan pesan yang akan disampaikan. Majaz kbitabi juga dapat dikatakan sebagai gabungan antara majaz, lughawi dan majaz isnadi. Sebab keduanya menjadi satu kesatuan untuk menemukan makna yang akan diungkapan dalam kandugan teks Alqur'an.

\section{Penutup}

Dari uraian di atas, dapat ditarik kesimpulan, bahwa majas secara umum sudah ada sebelum Islam dan Alqur'an diturunkan. Hal ini dibuktikan dengan adanya penggalian makna literal dan makna substansial (majar) yang dilakukan pada abad ketujuh dan kedelapan. Kaitannya dengan Alqur'an, majaa pun sudah ada pada masa Alqur'an diturunkan. Namun pengertian tentang makna maja yang ada pada masa itu hanya sebatas makna imtsal, bukan seperti yang dikenal pada masa sekarang.

20 Jorge J.E. Gracia, A Theory of Textuality (USA: State University of New York Press, 1995), 14. 
Pada masa pembentukan analisa makna secara menyeluruh, sebagaimana yang dilakukan oleh Muqatil dan yang ada pada saat ini, perdebatan itu belum ada. Sebab Muqatil hanya mengidentifikasi makna yang sering berganti-ganti, sementara sebab disesuaikan dengan qarinah dan konteks saat ayat diturunkan. Selain itu, majas telah diperkenalkan dari definisi dan ragamanya, sebagaimana yang dilakukan oleh Abu Ubaidah, meski tidak dikenal sebagai lawan dari haqiqah. Abu Ubaidah pun telah mengklarifikasi banyak ragam lafadz dalam Alqur'an yang mempunyai makna bukan pada tempatnya, itu ada juga yang dibuang. Setelah generasi Abu Ubaidah, perdebatan majaz berkembang, sebagaimana yang diusung oleh para ilmuan Islam, seperti para ahli ushul figh dan lughawiyun. Meskipun perdebatan panjang terjadi, tetapi hal itu tidak berdampak pada tatanan kebahasaan Alqur'an. Dengan kata lain, majaz tetap eksis menjadi bagian dari keindahan bahasa Alqur'an.

\section{Referensi}

Aldahlawi, Syah Waliyullah. Alfauzul Alkabir fi Ushul Altafsir. Kairo: Dar Syuhuh, 1986.

Aljabiri, Abiet. Binyat Alaql Alarabi, Dirasah Tabliyyah Naqdiyah li Nuqum Alma'rifah fi Altsaqafah Alarabiyah. Beirut: Almarkaz Astsaqafi, 1991.

Alsangqithi, Muhammad Amin ibn Muhammad Mukhtar ibn Abdul Qadir Aljakni. Man'u Jawaz. Almajaz fi Manzi Alta'abud wa I'jaz. Kairo: Darul Ilmi Alfuadi, n.d.

Althabari, Muhammad ibn Jarir ibn Yazid Abu Ja'far. Jami' Albayan fi Ta'wil Alquran. Beirut: Muasasah Alrisalah, 2000.

Alzamakhzyari, Alqasim Mahmud ibn Umar ibn Ahmad. Alkasysyaf Haqaiq Ghawam Altanzil. Beirut: Dar Kutub, n.d.

Amin, Ali Aljarim dan Mustafa. Albalaghah Alwabidah. Kairo: Dar Alma’arif, 1951. 
Gracia, Jorge J.E. A Theory of Textuality. USA: State University of New York Press, 1995.

Hasyim, Ahmad. Jawabir Albalaghab fi Alma'ani wa Albayan wa Albadi'. Libanon: Darul Kutub Alilmiyah, 1971.

Juwaini, Abdul Malik bin Abdullah Al-. Alwaraqat fi Ushul Alfiqh. Surabaya: Alhidayah, 1999.

Sukamta. Majaz dan Pluralitas Makna Dalam Alquran. Yogyakarta: Adab Press UIN Sunan Kalijaga, 2009.

Syamsuddin, Sahiron. Hermeneutika dan Pengembagnan Ulum Alquran. Yogyakarta: Wanesia, 2009.

Ubaidah, Abu. Majaz. Alquran. Kairo: Maktabah Nasher, n.d.

Yusuf, Abi Ishaq ibn Ali ibn. Alluma' fi Usbul Figh. Semarang: Taha Putra, n.d.

Zaid, Nash Hamid Abu. Naqd Alkbitab Aldiniy. Kairo: Maktabah Matbuli, 1992.

Zaid, Nasr Hamid Abu. Menalar Firman Tuban, Wacana Majaz dalam Alqur'an Menurut Mu'tazilah (Terj). Edited by Abdurahman Kasdi dan Hamka. Bandung: Mizan, 2003.

Zarkasyi. Alburban fi Ulum Alquran. Beirut: Dar Kutub, 1999. 